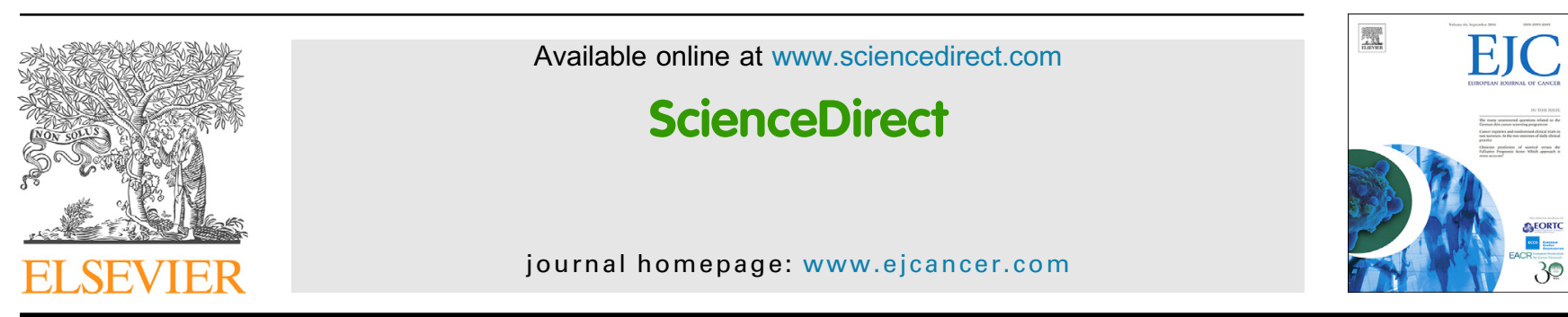

Original Research

\title{
Extraskeletal osteosarcoma: A European Musculoskeletal Oncology Society study on 266 patients ${ }^{\text {is }}$
}

A. Longhi ${ }^{\mathrm{a}, *}$, S.S. Bielack ${ }^{\mathrm{b}}$, R. Grimer ${ }^{\mathrm{c}}$, J. Whelan ${ }^{\mathrm{d}}$, R. Windhager ${ }^{\mathrm{e}}$, A. Leithner ${ }^{f}$, A. Gronchi ${ }^{g}$, D. Biau ${ }^{\text {h}}$, P. Jutte ${ }^{i}$, A.H. Krieg ${ }^{j}$, F.M. Klenke ${ }^{\mathrm{k}}$, G. Grignani ${ }^{1}$, D.M. Donati ${ }^{\mathrm{a}}$, R. Capanna ${ }^{\mathrm{m}}$, J. Casanova ${ }^{n}$, C. Gerrand ${ }^{\circ}$, G. Bisogno ${ }^{p}$, S. Hecker-Nolting ${ }^{b}$, M. De Lisa ${ }^{\text {d }}$, L. D’Ambrosio ${ }^{1}$, M. Willegger ${ }^{\text {e }}$, G. Scoccianti $^{\mathrm{m}}$, S. Ferrari ${ }^{\text {a }}$

a Istituto Ortopedico Rizzoli, Bologna, Italy

${ }^{\mathrm{b}}$ Klinikum Stuttgart, Olgahospital, Cooperative Osteosarcoma Study Group (COSS), Stuttgart, Germany

${ }^{\mathrm{c}}$ Royal Orthopaedic Hospital, Birmingham, UK

${ }^{\mathrm{d}}$ London Sarcoma Service, University College Hospital, UK

e Department of Orthopaedics, Medical University of Vienna, Vienna General Hospital, Vienna, Austria

${ }^{\mathrm{f}}$ Orthopaedic Surgery, Medical University Graz, Graz, Austria

g Chirurgia dei Sarcomi, Istituto Nazionale Tumori, Milano, Italy

${ }^{\text {h } C h i r u r g i e}$ Orthopédique, Hopital Cochin, Université Paris-Descartes, Paris, France

${ }^{i}$ University Medical Center, Groningen, The Netherlands

j Paediatric Orthopaedic Department, University Childrens Hospital (UKBB), Basel, Switzerland

${ }^{\mathrm{k}}$ INSELSPITAL, University Hospital, Bern, Switzerland

${ }^{1}$ Candiolo Cancer Institute - FPO, IRCCS, Italy

${ }^{\mathrm{m}}$ CTO, Careggi, Firenze, Italy

${ }^{\mathrm{n}}$ Orthopedic University Hospital, University of Coimbra, Coimbra, Portugal

${ }^{\circ}$ Freeman Hospital, Newcastle upon Tyne, UK

${ }^{\mathrm{p}}$ Oncoematologia Pediatrica, University of Padova, Padova, Italy

Received 17 October 2016; received in revised form 12 December 2016; accepted 24 December 2016

\section{KEYWORDS}

Extraskeletal

osteosarcoma;

\begin{abstract}
Purpose: Prognosis of extraskeletal osteosarcoma (ESOS) is reported to be poorer than that of skeletal osteosarcoma. This multicenter retrospective study aimed to evaluate factors influencing ESOS prognosis.
\end{abstract}

\footnotetext{
Poster presentation EMSOS 2015, ASCO 2015 Annual Meetings.

* Corresponding author: Chemotherapy Section, Istituto Ortopedico Rizzoli, Via Pupilli 1, 40136 Bologna, Italy.

E-mail address: alessandra.longhi@ior.it (A. Longhi).
} 
Localised osteosarcoma; EMSOS
Patients and methods: Members of the European Musculoskeletal Oncology Society (EMSOS) submitted institutional data on patients with ESOS.

Results: Data from 274 patients treated from 1981 to 2014 were collected from 16 EMSOS centres; 266 patients were eligible. Fifty $(18.7 \%)$ had metastases at diagnosis. Of 216 patients with localised disease, $211(98 \%)$ underwent surgery $(\mathrm{R} 0=70.6 \%, \mathrm{R} 1=27 \%)$. Five-year overall survival (OS) for all 266 patients was 47\% (95\% CI 40-54\%). Five-year OS for metastatic patients was $27 \%(95 \%$ CI $13-41 \%)$. In the analysis restricted to the 211 localised patients who achieved complete remission after surgery 5 -year OS was $51.4 \%$ (95\% CI $44-59 \%)$ and 5-year disease-free survival (DFS) was 43\% (95\% CI 35-51\%). One hundred twenty-one patients $(57.3 \%)$ received adjuvant or neoadjuvant chemotherapy and 80 patients $(37.9 \%)$ received radiotherapy. A favourable trend was seen for osteosarcoma-type chemotherapy versus soft tissue sarcoma-type (doxorubicin \pm ifosfamide) regimens. For the 211 patients in complete remission after surgery, patient age, tumour size, margins and chemotherapy were positive prognostic factors for DFS and OS by univariate analysis.

At multivariate analysis, patient age $(\leq 40$ years versus $>40$ years $)(P=0.05)$, tumour size $(\mathrm{P}=0.0001)$ and receipt of chemotherapy $(\mathrm{P}=0.006)$ were statistically significant prognostic factors for survival.

Conclusion: Patient age and tumour size are factors influencing ESOS prognosis. Higher survival was observed in patients who received perioperative chemotherapy with a trend in favour of multiagent osteosarcoma-type regimen which included doxorubicin, ifosfamide and cisplatin.

(c) 2017 Elsevier Ltd. All rights reserved.

\section{Introduction}

First reported in 1941, extraskeletal osteosarcoma (ESOS) is a rare mesenchymal tumour arising in soft tissue accounting for $1 \%$ of all soft tissue sarcomas and $4 \%$ of all osteosarcomas [1-3]. Several retrospective series have been reported, mostly with less than 50 patients. The largest series are shown in Table 1. Median age at diagnosis is in the fifth and sixth decade of life. In children, ESOS are much rarer than skeletal osteosarcoma [11]. Males prevail in all but one cohort. Aetiology is unknown, although $5-10 \%$ occur after radiotherapy (RT) and preceding trauma is reported in $12-13 \%$ [7]. An association with previous myositis ossificans has also been postulated [12].

ESOS usually occurs as a slow growing mass with a longer interval between symptom onset and diagnosis compared to skeletal osteosarcoma (median 6 versus 2 months) [4-8,14]. Common sites are limbs,

Table 1

ESOS larger cohort studies.

\begin{tabular}{|c|c|c|}
\hline $\begin{array}{l}\begin{array}{l}\text { Author } \\
\text { (year) }\end{array}\end{array}$ & $\begin{array}{l}\text { Total no. of patients } \\
\text { (localised) }\end{array}$ & Outcome \\
\hline Lee (1995) [8] & 40 & 5 -year OS $37 \%$ \\
\hline Ahmad (2002) [6] & $60(38)$ & $\begin{array}{l}5 \text {-year DFS } 46 \% \\
\text { (localised) }\end{array}$ \\
\hline Choi (2014) [9] & $53(42)$ & $\begin{array}{l}\text { 3-year OS 61\% } \\
\text { (localised) }\end{array}$ \\
\hline Thampi (2014) [10] & $256(188)$ & $\begin{array}{l}5 \text {-year OS } 37 \% \\
\text { (47\% in localised) }\end{array}$ \\
\hline Longhi (2017) & $266(211)$ & $\begin{array}{l}5 \text {-year OS } 47 \% \\
(51.4 \% \text { in localised) }\end{array}$ \\
\hline
\end{tabular}

ESOS $=$ extraskeletal osteosarcoma; OS $=$ overall survival; DFS $=$ disease free survival. retroperitoneum and chest wall [7], but 50 cases arising in the breast have been described [15]. These must be distinguished from matrix-producing epithelial breast carcinomas. Recommended criteria for ESOS of the breast include absence of an epithelial component and presence of malignant osteoid [15,16]. Histologically ESOS presents similar characteristics to those of skeletal osteosarcoma with a differing proportion of osteoid and cartilaginous and fibrous tissue [13]. It is high grade though exceptionally may be well differentiated [1].

ESOS relapse rate is over 75\% [13]. Distant metastases occur most frequently in lungs, lymph nodes and bone [7].

Surgical resection is the standard treatment. ESOS are considered poorly responsive to chemotherapy: Ahmad et al. [6] reported only 19\% response (complete remission $[\mathrm{CR}]+$ partial remission $[\mathrm{PR}]$ to doxorubicinbased chemotherapy and $13 \%$ to cisplatin-based chemotherapy. However, because of the perceived similarities to skeletal osteosarcoma, the role of chemotherapy is debated.

This retrospective study, performed under the auspices of EMSOS, aimed to improve knowledge on the natural history of ESOS, identify prognostic factors and inform on the role of chemotherapy treatment.

\section{Patients and methods}

A request was sent to EMSOS members to participate in the study with study information available on the society website (www.emsos.org). All participating centres obtained ethical approval. All centres were provided 
with a case report form for collection of anonymised data.

From March 2014 to December 2015 data for 274 patients treated from 1981 to 2014 from 16 centres or cooperative groups were submitted for analysis. For this study we accepted a time lapse of 33 years due to rarity of the disease and considering that not many changes occurred in this period for ESOS treatment. Analyses were performed by descriptive statistics. Median follow up for the 266 patients was 22.5 months (range 1-384 months).

Overall survival (OS) was calculated from diagnosis to death or last follow up, disease-free survival (DFS) was calculated from date of surgery to relapse/progression or last follow up by the Kaplan-Meier method. The time scale was extended to the last follow up if none of these events were observed. Log-rank test was used to compare survival curves for the different subgroups of patients. Statistical significance of each variable was then tested by multivariate analysis using the stepwise model and Cox regression analysis. Osteosarcoma-type chemotherapy corresponds to the multidrug regimen similar to that used for bone osteosarcoma with cisplatin, doxorubicin, ifosfamide, methotrexate and sometimes etoposide. Soft tissue sarcoma-type chemotherapy corresponds to a regimen similar to that used for soft tissue sarcomas (an anthracycline with or without ifosfamide).

\section{Results}

Two hundred sixty-six patients had adequate data for analysis. Patient characteristics are reported in Table 2. There was a higher incidence of male gender $(\mathrm{M}: \mathrm{F}=1.5: 1)$. Median age was 57 years (range, 12-91). The median interval from symptom onset to diagnosis

Table 2

Patient characteristics; all 266 pts (left) and 211 pts with localised ESOS (right).

\begin{tabular}{lll}
\hline & All patients (266) & $\begin{array}{l}\text { Pts with localised } \\
\text { disease (211) }\end{array}$ \\
\hline $\begin{array}{l}\text { Median age years } \\
\text { Gender }\end{array}$ & $57(12-91)$ & $57(12-91)$ \\
- Male & $162 \mathrm{M}: \mathrm{F}=1.5: 1$ & $128 \mathrm{M}: \mathrm{F}=1.5: 1$ \\
- Female & 104 & 83 \\
Stage & & \\
- Localised & $216(80.8 \%)$ & 211 \\
- * Metastatic & $50(18.7 \%)$ & - \\
Site of primary tumour & & \\
- Extremity & $221(83 \%)$ & $180(85.7 \%)$ \\
- Non-extremity & $45(16.9 \%)$ & $31(14.3 \%)$ \\
$\quad$ Chest & 25 & 17 \\
$\quad$ Abdomen & 8 & 3 \\
$\quad$ Viscera & 6 & 5 \\
$\quad$ Breast & 6 & 6
\end{tabular}

ESOS = extraskeletal osteosarcoma; Pts = patients; $*$ Metastatic at diagnosis. was 5 months (range $0-130$ months) with some cases of very late diagnosis. Median tumour size was $10 \mathrm{~cm}$ (range 2-50 cm). Histologic subtype distribution was similar to that of skeletal osteosarcoma [1]. Most cases were categorised as high grade osteosarcoma without specification of subtype. Three patients had a previous diagnosis of myositis ossificans in the site where ESOS occurred. Twelve patients had 13 different previous malignancies. ESOS was a radiotherapy-induced secondary malignancy in 5 of these 12 patients: 1 nonHodgkin lymphoma, 1 fibrosarcoma, 1 rhabdomyosarcoma and 2 Ewing sarcomas, after a mean interval of 17.7 years ( $7-38$ yrs). Five-year OS for the 266 patients was $47 \%(95 \%$ CI $40-54 \%)$ and $51.4 \% \quad(95 \%$ CI 44-59\%) for the 211 patients with localised disease $(\mathrm{P}<0.0001)$ after surgical excision (Fig. 1).

Six patients developed a second malignancy after ESOS (two kidney carcinoma, one bladder carcinoma, one prostate cancer and two acute myeloid leukaemia [AML]). The 2 patients (15-year old male and 54-year old female) who developed AML received osteosarcoma-type chemotherapy and no RT and AML was probably in correlation with chemotherapy. The other tumours occurred in patients over 70 years of age. The 2 patients with secondary kidney carcinoma and the patient with prostate cancer received only chemotherapy. The patient of 73 with ESOS of shoulder treated with local RT developed a bladder cancer 13 years later. So apart from AML, the other secondary cancers could be related more to age of patients.

\subsection{Patients with metastases}

Fifty patients had metastases at diagnosis: median age 58.5 years (range, $13-87$ years), 32 male and 18 female, 40 patients had one metastatic site, ten had multiple sites. Lung metastases were reported in 42/50 patients, bone in four, lymph nodes in six, abdominal metastases

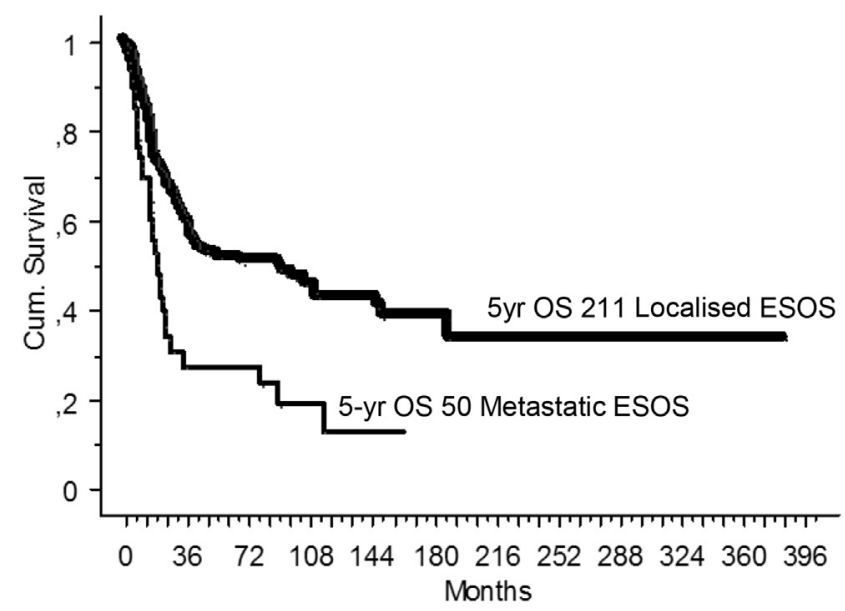

Fig. 1. 5-year overall survival of localised versus metastatic extraskeletal osteosarcoma ( $\mathrm{P}<0.0001)$. 
in three (1 in omentum, 2 abdomen not otherwise specified), liver metastases in two and brain metastases in 1 patient.

Chemotherapy was administered in 36 of the 50 metastatic patients at presentation. 28/36 (77.7\%) received an osteosarcoma-type regimen: five received doxorubicin-cisplatin, 11 doxorubicin-cisplatin-ifosfamide, nine doxorubicin-cisplatin-ifosfamide-methotrexate, two doxorubicin-cisplatin-ifosfamide-etoposide and one doxorubicin-cisplatin-ifosfamide-methotrexateetoposide. Eight patients received a soft tissue sarcomatype scheme: four a combination of doxorubicin + ifosfamide, three doxorubicin alone and one only high dose ifosfamide. RT was given to 14 patients, in 11 it was associated with chemotherapy. Two patients received only best supportive care. Thirty-three of 50 patients were already dead at the onset of the study, with a median follow up of 19 months (range, 1-142 months), the 5-year OS for the 50 metastatic patients was $27 \%(95 \%$ CI $13-41 \%)$.

\subsection{Patients with localised disease}

Of the 216 patients with localised disease at diagnosis, 211 underwent surgical resection of the primary tumour, in $5 / 216(2.3 \%)$ no surgery was performed (primary site:
1 neck, 1 chest, 1 thigh, 2 pelvises). Of these patients, three received only local palliative RT, the other two received chemotherapy alone. Data of 211 localised patients are reported in Table 3.

Forty-six (21.8\%) had surgery alone, 43 (20.3\%) had surgery + RT, $83(39.3 \%)$ had surgery + chemotherapy and $37(17.5 \%)$ received surgery + $\mathrm{RT}+$ chemotherapy. In two cases treatment was unknown. Surgical margins were reported as R0 in 149 $(70.6 \%)$ patients, R1 in 57 (27\%) and unknown in five. In this group of 211 patients with resected localised disease, 5-year OS and 5-year DFS were 51.4\% (95\% CI $44-59 \%)$ and $43 \%$ (95\% CI 35-51\%), respectively (Fig. 2). One hundred twenty-one of 211 (57.3\%) patients with localised disease were alive at time of data lock; 77/90 (85.5\%) died of ESOS; 13 patients died of causes unrelated to ESOS treatment (12 of whom had no recurrence reported): 2/13 died of a haematologic second malignancy (one AML and one myelodysplastic syndrome (MDS) which progressed to AML). The 2 patients who developed an AML received chemotherapy osteosarcoma-type and no RT. One case was a 15-year old male, who after 2 years from diagnosis of ESOS developed AML, the other was a 54 year old female, who developed a MDS 3 years after ESOS treatment and after another 4 months MDS turned into AML.

Table 3

5-year DFS and 5-year OS in 211 patients with localised ESOS.

\begin{tabular}{|c|c|c|c|c|}
\hline & & No. of Pts & 5-year DFS $(95 \% \mathrm{CI})$ & 5-year OS $(95 \% \mathrm{CI})$ \\
\hline & & 211 & $43 \%(35-51)$ & $51.4 \%(44-59)$ \\
\hline \multirow[t]{3}{*}{$\overline{\text { Gender }}$} & Male & $128(60.6 \%)$ & $40 \%(31-50)$ & $48 \%(39-58)$ \\
\hline & Female & $83(39.3 \%)$ & $46 \%(33-59)$ & $56.5 \%(44-69)$ \\
\hline & & & $\mathrm{P}=0.2$ & $P=0.9$ \\
\hline \multirow[t]{5}{*}{ Age } & $\leq 18$ years & $16(7.5 \%)$ & $67 \%(43-91)$ & $58 \%(32-84)$ \\
\hline & $\overline{19}-40$ years & $32(15.1 \%)$ & $65 \%(46-84)$ & $71 \%(52-89)$ \\
\hline & $41-65$ years & $98(46.4 \%)$ & $45 \%(33-56)$ & $57 \%(46-68)$ \\
\hline & $>65$ years & $65(30.8 \%)$ & $18 \%(6-31)$ & $29 \%(16-43)$ \\
\hline & & & $\mathrm{P}=0.0003$ & $\mathrm{P}=0.0001$ \\
\hline \multirow[t]{4}{*}{ Size } & $\leq 5 \mathrm{~cm}$ & $42(19.9 \%)$ & $74 \%(59-90)$ & $78 \%(64-92)$ \\
\hline & $5-10 \mathrm{~cm}$ & $80(37.9 \%)$ & $34 \%(22-45)$ & $46 \%(34-58)$ \\
\hline & $>10 \mathrm{~cm}$ & $72(42.1 \%)$ & $30 \%(16-44)$ & $34 \%(21-47)$ \\
\hline & Unknown & 17 & $\mathrm{P}=0.0001$ & $\mathrm{P}=0.0001$ \\
\hline \multirow[t]{3}{*}{ Margins } & $\mathrm{R} 0$ & $149(70.6 \%)$ & $51 \%(42-61)$ & $58 \%(48-67)$ \\
\hline & $\mathrm{R} 1$ & $57(27 \%)$ & $24 \%(10-37)$ & $37 \%(23-52)$ \\
\hline & Unknown & 5 & $\mathrm{P}=0.002$ & $P=0.006$ \\
\hline \multirow[t]{3}{*}{ RT } & Yes & $80(37.9 \%)$ & $46 \%(36-56)$ & $52 \%(40-65)$ \\
\hline & No & $128(60.6 \%)$ & $40 \%(28-52)$ & $52 \%(42-62)$ \\
\hline & Unknown & 3 & $\mathrm{P}=0.3$ & $\mathrm{P}=0.5$ \\
\hline \multirow[t]{5}{*}{ Treatment } & Surgery alone & $46(21.8 \%)$ & $26 \%(10-42)$ & $37 \%(21-53)$ \\
\hline & Surgery + CT & $83(39,3 \%)$ & $56 \%(44-68)$ & $60 \%(48-73)$ \\
\hline & Surgery + RT & $43(20.3 \%)$ & $27.5 \%(12-43)$ & $40 \%(24-56)$ \\
\hline & Surgery $+\mathrm{CT}+\mathrm{RT}$ & $37(17.5 \%)$ & $52 \%(35-69)$ & $64 \%(46-81)$ \\
\hline & Unknown & 2 & $\mathrm{P}=0.02$ & $P=0.002$ \\
\hline \multirow[t]{3}{*}{ Chemo } & Yes & $121(57.3 \%)$ & $55 \%(45-65)$ & $62 \%(51-72)$ \\
\hline & No & $86(40.7 \%)$ & $27 \%(16-38)$ & $38 \%(26-49)$ \\
\hline & Unknown & 4 & $\mathrm{P}=0.003$ & $\mathrm{P}=0.0002$ \\
\hline \multirow[t]{3}{*}{ Chemo type } & Osteo-type & $69(57.5 \%)$ & $62 \%(49-75)$ & $65 \%(52-79)$ \\
\hline & STS-type & $43(35.8 \%)$ & $48 \%(32-64)$ & $59 \%(42-75)$ \\
\hline & Unknown & 9 & $\mathrm{P}=0.05$ & $\mathrm{P}=0.08$ \\
\hline
\end{tabular}

ESOS $=$ extraskeletal osteosarcoma DFS $=$ disease-free survival; OS $=$ overall survival. 


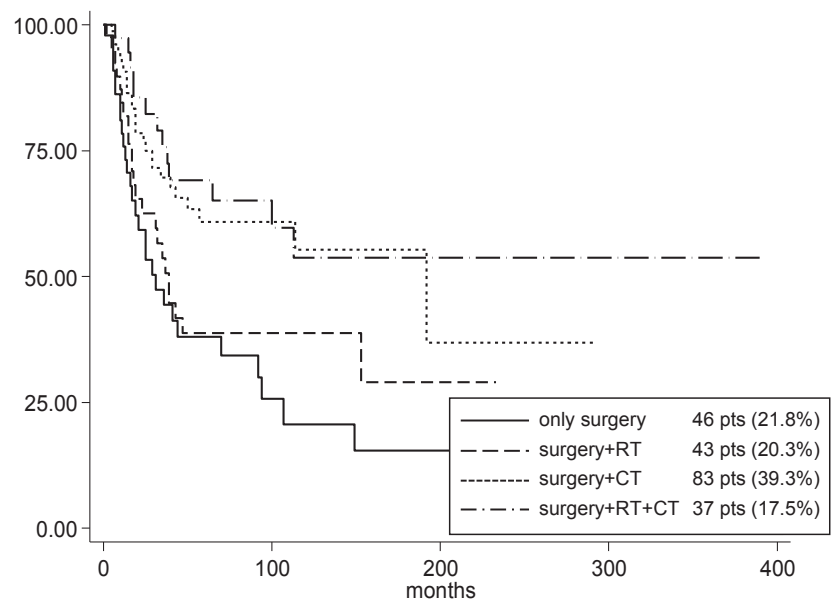

Fig. 2. 5-year overall survival and treatment $(\mathrm{P}=0.002)$.

Radiation therapy was administered in $80(37.9 \%)$ patients. In $55(68.7 \%)$ RT was administered postoperatively, in $5(6 \%)$ preoperatively, in $3(4 \%)$ RT was palliative, in the remaining 17 (21\%) timing of RT was unknown. Median dose was 58 Gy (36-79 Gy).

Chemotherapy was administered in $121(57.3 \%)$ patients. In 32/121 as neoadjuvant (preoperative), in 75 as adjuvant and in the remaining 14 it was not specified an osteosarcoma-type regimen of chemotherapy was administered in $69(57.5 \%)$ patients. A soft tissue-type regimen was administered to 43 patients $(35.8 \%)$. In the remaining 9 patients $(7.4 \%)$ the type of chemotherapy was unknown. All together 68/69 received doxorubicin, 65/69 received cisplatin; 58/69 received ifosfamide and 27 received methotrexate. The combinations were the following: 10 patients received cisplatin and doxorubicin, 28 doxorubicin-cisplatin-ifosfamide, 23 doxorubicin-cisplatin-ifosfamide-methotrexate, four doxorubicin-cisplatin-ifosfamide-methotrexate-etoposide and carboplatin and three received VIDE (vincristine, ifosfamide, doxorubicin, etoposide) chemotherapy.

Median number of cycles for patients treated with osteosarcoma-type chemotherapy was 5 (range 2-20).

Thirty-six patients treated with soft tissue sarcomatype chemotherapy received a combination of an anthracycline associated with ifosfamide. Only 5 patients received anthracycline as single agent, 2 received etoposide and ifosfamide without anthracycline. The median number of chemotherapy cycles per patient was 3 (range 1-12).

Table 3 reports the 5-year DFS and OS according to patient characteristics and treatment. Five-year DFS and OS were significantly better $(P=0.003$ and $\mathrm{P}=0.0002$, respectively) in patients selected to receive chemotherapy (Fig. 3).

\subsection{Distribution of treatment according to patient age, tumour margins and size}

These data are reported in Table 4. Chemotherapy was given to $52.3 \%$ patients with tumours $<5 \mathrm{~cm}$, in $57.5 \%$ in

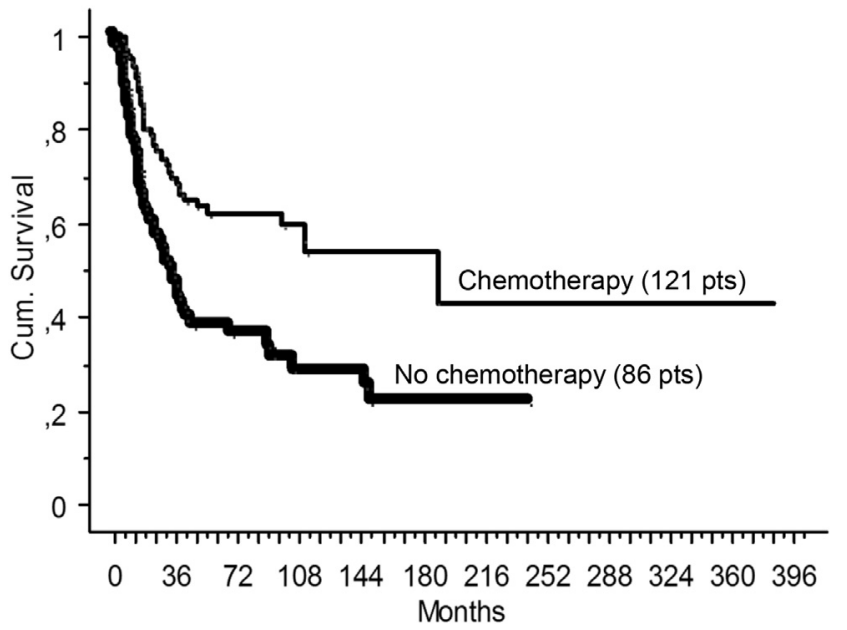

Fig. 3. 5-year overall survival for chemotherapy versus no chemotherapy $(\mathrm{P}=0.0002)$.

tumour $\geq 5-10 \mathrm{~cm}$ and in $61.3 \%$ when the tumour was $>10 \mathrm{~cm}(\mathrm{P}=0.64)$. Chemotherapy was administered more frequently in patients younger than 65 years $(P=0.0001)$. The use of chemotherapy in tumours $>5 \mathrm{~cm}$ was a significant prognostic factor for 5-year DFS (Fig. 4). Median DFS of patients who received an osteosarcoma-type regimen was 31.2 months $(2-184)$ compared to 14.9 months $(2-384)$ of those who received an soft tissue sarcoma (STS) type chemotherapy $(\mathrm{P}=0.003)$. Patients treated with adjuvant osteosarcoma-type chemotherapy reported a 5-year DFS of $62 \%(95 \%$ CI $49-75 \%)$ versus $48 \%$ (95\% CI $32-64 \%$ ) in STS-type chemotherapy with a trend of statistical significance in favour of osteosarcoma-type chemotherapy ( $\mathrm{P}=0.05)$ (Fig. 5). There was no difference in choice of administration of RT according to tumour size or surgical margins.

\subsection{Relapse}

104/211 (49.2\%) patients relapsed: 52 relapsed locally, 88 had distant metastases, 36 relapsed both locally and

Table 4

Distribution of treatment in 211 patients with localised ESOS according to age, margins, size.

\begin{tabular}{lllll}
\hline & $\begin{array}{l}\text { Surgery } \\
(\%)\end{array}$ & $\begin{array}{l}\text { Surgery and } \\
\text { RT }(\%)\end{array}$ & $\begin{array}{l}\text { Surgery }+ \\
\text { Chemo } \pm \text { RT }(\%)\end{array}$ & P value \\
\hline Age & & & & $\mathrm{P}=0.0001$ \\
$\leq 18$ & 6.2 & 6.2 & 87 & \\
$19-40$ & 9.3 & 12.5 & 78 & \\
$41-65$ & 17.3 & 13.2 & 69 & $\mathrm{P}=0.01$ \\
$>65$ & 39.6 & 39.6 & 20.6 & \\
Margins & & & & $\mathrm{P}=0.69$ \\
R0 & 20.9 & 16.2 & 62 & \\
R1 & 26.7 & 32.1 & 41 & \\
Size & & & & \\
$\leq 5 \mathrm{~cm}$ & 23.8 & 26.1 & 50 & \\
$5-10 \mathrm{~cm}$ & 18.8 & 24 & 56.9 & \\
$>10 \mathrm{~cm}$ & 23.9 & 16.9 & 59.1 & \\
\hline
\end{tabular}

ESOS $=$ extraskeletal osteosarcoma; $\mathrm{RT}=$ radiotherapy. 


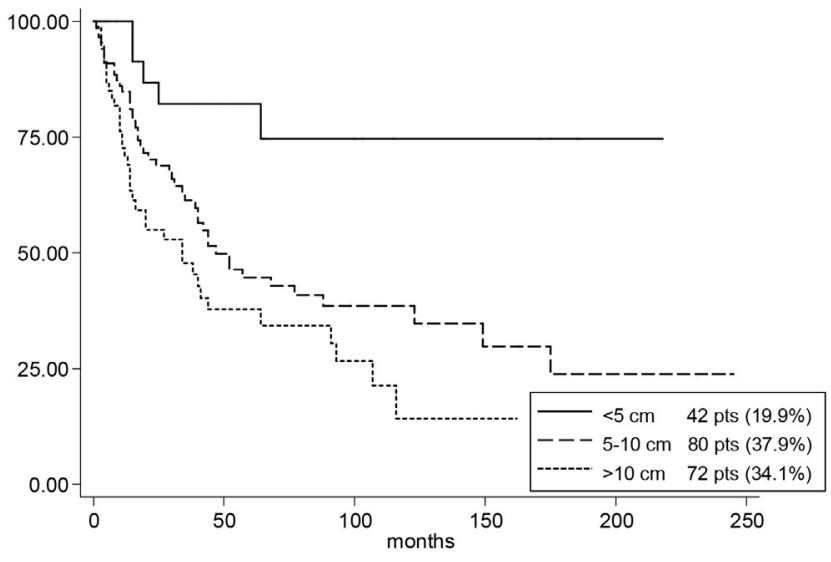

Fig. 4. 5-year disease-free survival and size $(\mathrm{P}=0.0002)$.

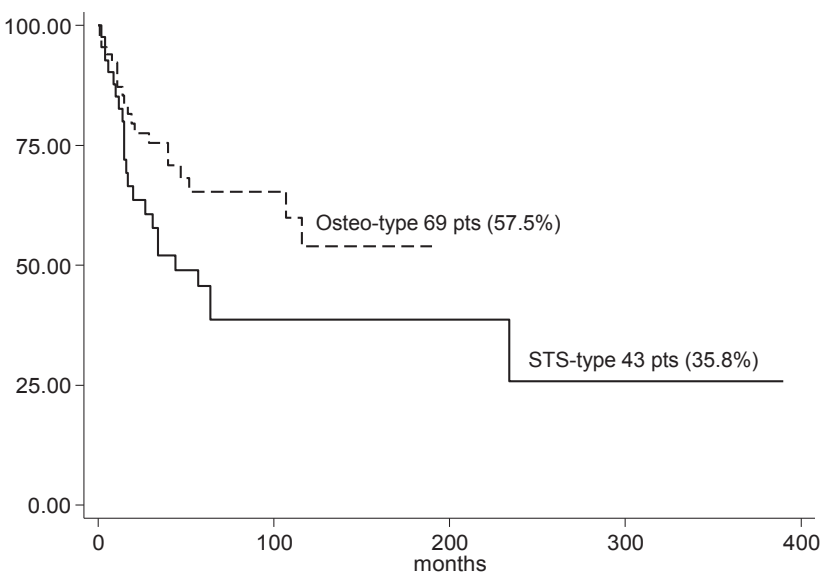

Fig. 5. 5-year disease-free survival and type of chemotherapy: osteosarcoma-type versus soft tissue-type chemotherapy $(\mathrm{P}=0.05)$.

distantly and 10 of these being simultaneous. Median time to relapse was 12 months $(1-185)$, median time to local relapse was 13 months $(2-116)$ and median time to distant metastases was 11 months $(2-185)$. Twelve patients had more than one distant metastatic site. Sites of metastases were: lung in 64 patients, bone in 7, lymph node in 5 , soft tissue in 4 , brain in 3 , liver in 2 , abdomen in 2 and breast in 1 .
For local relapse 22/52 patients received surgery alone, six received surgery $+\mathrm{RT}$, six received surgery + chemotherapy, 1 surgery + RT + chemotherapy, 2 chemotherapy alone and 3 as palliative treatment. In 12 patients treatment was not reported.

Treatment for distant relapse was unknown in 27/88 cases, treatment was surgery alone in 18 , chemotherapy alone in 16 , surgery + chemotherapy in ten, surgery $+\mathrm{RT}$ in four, chemotherapy $+\mathrm{RT}$ in three and best support in ten.

For the few patients with clinical data after local or distant relapse the majority received gemcitabine-based chemotherapy which is used in STS and as well in osteosarcoma.

A further subanalysis of local relapse free survival (LRFS) of the 31/52 patients with local relapse as only site or first site of relapse (6 months before any further relapse) showed a 5-year LRFS of $77 \% \quad(95 \%$ CI 69-85\%). Positive prognostic factors for LRFS were: margins $(P=0.05)$ and chemotherapy $(P=0.04)$. At multivariate analysis chemotherapy was the most important prognostic factor for LRFS $(\mathrm{P}=0.004)$, RT $(\mathrm{P}=0.07)$ was not significant.

Distant metastases free survival (DMFS) on 78 patients with distant metastases as unique or first site of relapse had a 5-year DMFS of 55\% (95\% CI 47-64\%). Significant prognostic factors were size $(\mathrm{P}=0.002)$, margins $(P=0.004)$ and chemotherapy $(P=0.004)$. At multivariate analyses only size $(\mathrm{P}=0.003)$ and chemotherapy $(\mathrm{P}=0.001)$ were significant.

All these results should be taken cautiously because the cohort is small and heterogeneous.

\subsection{Radiotherapy and local relapse (Table 5)}

Local relapse rate was not statistically different for patients who received RT $(\mathrm{P}=0.7)$. RT decreased the incidence of local relapse for patients with tumour $>5 \mathrm{~cm}(\mathrm{P}=0.054)$ and in patients with tumour $>5 \mathrm{~cm}$ and R0 margins: local relapse occurred in $17 / 61(28 \%)$ in the no RT group versus $4 / 37(11 \%)$ in the RT group $(\mathrm{P}=0.05)$. For patients with tumour $>5 \mathrm{~cm}$ and $\mathrm{R} 1$ margins no statistically significant difference was

Table 5

Radiotherapy and local relapse.

\begin{tabular}{|c|c|c|c|c|}
\hline Radiotherapy & \# Patients & No local relapse & Local relapse & $\mathrm{P}$ value \\
\hline No RT in tumours $>5 \mathrm{~cm}$ & 87 & $59(68 \%)$ & $28(32 \%)$ & 0.054 \\
\hline Yes RT in tumours $>5 \mathrm{~cm}$ & 61 & $50(82 \%)$ & $11(18 \%)$ & \\
\hline No RT in tumours $>10 \mathrm{~cm}$ & 40 & $28(70 \%)$ & $12(30 \%)$ & 0.1 \\
\hline Yes RT in tumours $>10 \mathrm{~cm}$ & 29 & $25(86 \%)$ & $4(14 \%)$ & \\
\hline No RT in tumour margin $\mathrm{R} 1$ & 32 & $20(62.5 \%)$ & $12(37.5 \%)$ & 0.9 \\
\hline Yes $\mathrm{RT}$ in tumour margin $\mathrm{R} 1$ & 29 & $18(86 \%)$ & $11(38 \%)$ & \\
\hline No $\mathrm{RT}$ in $\mathrm{R} 0$ only $\mathrm{T}>5 \mathrm{~cm}$ & 61 & $44(72 \%)$ & $17(28 \%)$ & 0.05 \\
\hline Yes RT in R0 only $\mathrm{T}>5 \mathrm{~cm}$ & 37 & $33(89 \%)$ & $4(11 \%)$ & \\
\hline No $\mathrm{RT}$ in $\mathrm{R} 1$ only $\mathrm{T}>5 \mathrm{~cm}$ & 26 & $15(58 \%)$ & $11(42 \%)$ & 0.3 \\
\hline Yes RT in R1 only $\mathrm{T}>5 \mathrm{~cm}$ & 24 & $17(71 \%)$ & $7(29 \%)$ & \\
\hline
\end{tabular}

$\mathrm{RT}=$ radiotherapy; $\mathrm{T}=$ tumour; $\mathrm{R} 0$ and $\mathrm{R} 1$ margin according to Union for International Cancer Control (UICC) margin classification. 
Table 6

Multivariate analysis.

\begin{tabular}{lll}
\hline Variable & Relative risk & P value \\
\hline $\begin{array}{l}\text { Age } \\
\leq 40 \mathrm{yrs}\end{array}$ & 1 & \\
$\quad>40 \mathrm{yrs}$ & $0.49(95 \%$ CI $0.25-0.99)$ & $\mathrm{P}=0.05$ \\
$\begin{array}{l}\text { Size } \\
>10 \mathrm{~cm}\end{array}$ & 1 & \\
$\leq 10 \mathrm{~cm}$ & $0.38(95 \%$ CI $0.24-0.6)$ & $\mathrm{P}=0.0001$ \\
$\begin{array}{l}\text { Chemotherapy } \\
\text { Yes CT }\end{array}$ & 1 & \\
$\quad$ No CT & $1.92(95 \%$ CI $1.2-3.1)$ & $\mathrm{P}=0.006$ \\
Margins & & \\
$\quad$ R 1 & 1 & $\mathrm{P}=0.075$ \\
R0 & $0.65(95 \%$ CI $0.4-1.1)$ & \\
\hline
\end{tabular}

observed for local relapse in relation to $\mathrm{RT}(\mathrm{P}=0.3)$. Seen the paucity of patients who underwent adjuvant $\mathrm{RT}$ its role in ESOS must be further examined.

At univariate analysis for 5-year DFS the significant prognostic factors were size, age, margins, chemotherapy and type of chemotherapy for the 211 patients with localised resected disease. Size, age, margins and chemotherapy use were statistically significant for 5-year OS. Sex, RT and type of chemotherapy were not statistically significant (Table 3). At multivariate analysis: size, age and chemotherapy were statistically significant prognostic factors (Table 6).

\subsection{Chemotherapy and radiotherapy choice according to EMSOS centers}

The use of chemotherapy and RT as adjuvant treatment varied between centres. Some centres administered chemotherapy in $80-90 \%$ of patients and RT in no more than $20 \%$. In other centres there was a prevalent use of RT (maximum in 48\%) and chemotherapy was employed only in $30 \%$ of patients. Patients treated with osteosarcoma-type regimens were given less RT compared to those treated with STS-type regimens (respectively, $11 \%$ and $66.6 \%$ ).

\section{Discussion}

This study reports the largest cohort of this rare sarcoma subtype and is notable for management having been undertaken in specialist centres defined by membership of EMSOS. While reinforcing information about the clinical features, it is most valuable in highlighting the uncertainties about best management of ESOS, illustrated by the variation in use of different treatment modalities between centres. The data presented about a potential value for adjuvant chemotherapy is stimulating but should be considered with caution.

The major limitations of the study are that it is retrospective and the heterogeneity in treatment strategy observed between participating centres. That said, to gather adequate amount of data on such a rare disease would not have been possible without a multicenter effort carried out by several referral centres throughout Europe.

In this cohort of ESOS, as seen in other studies with a population of similar age, 5-year DFS is less than $50 \%(47 \%)$ compared to that of about $60-65 \%$ $[17,18]$ in localised skeletal osteosarcoma patients under 40 years. A previous EMSOS study on 481 patients older than 40 years with localised skeletal osteosarcoma by Grimer [19] reported a 5-year OS of $46 \%$ similar to the 5 -year OS of $51.4 \%$ reported in this study.

Although ESOS is classified as a soft tissue sarcoma there is a significant trend of greater responsiveness to osteosarcoma-type chemotherapy (methotrexate, cisplatin, doxorubicin, ifosfamide) compared to only anthracycline-based \pm ifosfamide chemotherapy as usually employed in soft tissue sarcoma. Other papers $[5,20,21]$ have reported response to regimens including cisplatin. A recent study on 55 patients with ESOS reported an advantage in OS and progression free survival for patients who received chemotherapy including cisplatin versus those treated without cisplatin [20]. Another study on 17 patients from the Cooperative Osteosarcoma Study Group (COSS) reported a favourable 3- and 5-year estimated DFS of $77 \%$ after multimodal treatment including osteosarcoma-type chemotherapy (doxorubicin, cisplatin, ifosfamide, methotrexate) [21].

RT was administered in a small group of patients, about one third (80/211). It was mainly adjuvant, and used more frequently in patients with $\mathrm{R} 1$ margins and in those who received STS-type chemotherapy. There was no difference in the choice of RT administration according to age, size of primary tumour. Notably, RT seems to give an advantage in those patients with tumour $>5 \mathrm{~cm}$ and $\mathrm{R} 0$ margins, whereas no benefit was seen in patients with $\mathrm{R} 1$ margins confirming that inadequate surgery cannot be overcome by $\mathrm{RT}$. It seems that those centres which treated ESOS as a soft tissue sarcoma were more likely to use RT compared to those who treated ESOS with osteosarcoma-type chemotherapy. In this series adjuvant chemotherapy was a positive prognostic factor for both OS and DFS. The positive trend for an osteosarcoma-type chemotherapy regimen was observed for DFS but not for OS.

For patients with localised ESOS, complete surgical resection is necessary. The role of adjuvant RT and chemotherapy remains unclear from this study and argues for prospective randomised allocation but such a study is likely to prove impossible to conduct. In the meantime, selection of patients for multiagent chemotherapy and RT should be strongly considered, preferably by multidisciplinary teams working in specialist referral centres. 


\section{Conflict of interest}

None declared.

\section{Acknowledgements}

The authors thank the data managers of the collaborating centres and groups for their valuable assistance and Stefano Ferrari, MD for statistical assistance. Thanks to Alba Balladelli and Cristina Ghinelli for editing support.

\section{References}

[1] Campanacci M. Bone and soft tissue tumors. 2nd ed. Springer Verlag; 1999. p. 1190-1.

[2] Rosenberg AE, Heim S. Extraskeletal osteosarcoma. In: DM Fletcher C, Unni KK, Mertens F, editors. WHO Classification of tumors. Pathology and genetics of tumors of soft tissue and bone. Lyon: IARC press; 2002. p. 182-3.

[3] Wilson H. Extraskeletal ossifying tumors. Ann Surg 1941;113: 95-112.

[4] Allan CJ, Soule EH. Osteogenic sarcoma of the somatic soft tissues. Clinicopathologic study of 26 cases and review of literature. Cancer 1971;27:1121-33.

[5] Sordillo PP, Hajdu SI, Magill GB, Golbey RB. Extraosseous osteogenic sarcoma. A review of 48 patients. Cancer 1983;51: $727-34$.

[6] Ahmad SA, Patel SR, Ballo MT, Baker TP, Yasko AW, Wang X, et al. Extraosseous osteosarcoma: response to treatment and longterm outcome. J Clin Oncol 2002;20:521-7.

[7] Chung EB, Enzinger FM. Extraskeletal osteosarcoma. Cancer 1987;60:1132-42.

[8] Lee JS, Fetsch JF, Wasdhal DA, Lee BP, Pritchard DJ, Nascimento AG. A review of 40 patients with extraskeletal osteosarcoma. Cancer 1995;76:2253-9.

[9] Choi LE, Healey JH, Kuk D, Brennan MF. Analysis of outcomes in extraskeletal osteosarcoma: a review of fifty-three cases. J Bone
Joint Surg Am 2014;96:e2. http: //dx.doi.org/10.2106/JBJS.M.00339.

[10] Thampi S, Matthay KK, Boscardin WJ, Goldsby R, DuBois SG. Clinical features and outcomes differ between skeletal and extraskeletal osteosarcoma. Sarcoma 2014. Article ID 902620.

[11] Beall DP, Ly J, Bell JP, Parker EE. Pediatric extraskeletal osteosarcoma. Pediatr Radiol 2008;38(5):579-82. May.

[12] Shanoff LB, Spira M, Hardy SB. Myositis ossificans: evolution to osteogenic sarcoma. Report of a histologically verified case. Am J Surg 1967;113:537-41.

[13] Huvos AG. Osteogenic sarcoma of bones and soft tissues in older persons. A clinicopathological analysis of 117 patients older than 60 years. Cancer 1986;57:1442-9.

[14] Bacci G, Ferrari S, Longhi A, Mellano D, Giacomini S, Forni C. Delay in diagnosis of high-grade osteosarcoma of the extremities. Has it any effect on the stage of disease? Tumori 2000;86:204-6.

[15] Silver SA, Tavassoli FA. Primary osteogenic sarcoma of the breast: a clinicopathologic analysis of 50 cases. Am J Surg Pathol 1998;22(8):925-33.

[16] Rakha EA, Tan PH, Shaaban A, Tse GM, Esteller FC. Do primary mammary osteosarcoma and chondrosarcoma exist? A review of a large multi-institutional series of malignant matrixproducing breast tumours. Breast 2013;22(1):13-8.

[17] Bacci G, Longhi A, Versari M, Mercuri M, Briccoli A, Picci P. Prognostic factors for osteosarcoma of the extremity treated with neoadjuvant chemotherapy: 15-year experience in 789 patients treated at a single institution. Cancer 2006;106:1154-61.

[18] Benjamin SR. Primary extraskeletal osteosarcoma-experience with chemotherapy. J Natl Cancer Inst 1995;87:1331-3.

[19] Grimer RJ, Cannon SR, Taminiau AM, Bielack S, KempfBielack B, Windhager R, et al. Osteosarcoma over the age of forty. Eur J Cancer 2003;39:157-63.

[20] Paludo J, Fritchie K, Haddox C. Outcomes of extraskeletal osteosarcoma patients and role of perioperative chemotherapy. J Clin Oncol 2016;34:21 (suppl; abstr 11025).

[21] Goldstein-Jackson SY, Gosheger G, Delling G, Berdel WE, Exner GU, Jundt G, et al. Extraskeletal osteosarcoma has a favourable prognosis when treated like conventional osteosarcoma. J Cancer Res Clin Oncol 2005;131:520-6. 